\title{
Modeling of the Hydrological Cycle of a Forest River Basin and Hydrological Consequences of Forest Cutting
}

\author{
L.S. Kuchment" ${ }^{*}$ A.N. Gelfan and V.N. Demidov \\ Institute of Water Problems of the Russian Academy of Sciences, (IWP RAS), Moscow, Russia
}

\begin{abstract}
Physically based model of the hydrological cycle of a forest basin was developed. The model includes description of processes of liquid water and snow interception by forest canopy, snow accumulation and melt, vertical soil moisture transfer and evapotranspiration, overland, subsurface and channel flow. The case-study has been carried out on the basis of experimental observations on the Valday water balance station, situated in the north-western part of Russia. The model has been calibrated and validated using 5-year hydrometeorological observations at the completely forested Tayozhny Creek experimental basin. Then the 17-years hydrometeorological observations were used to estimate the possible change of hydrological cycle of this basin after forest cutting. The numerical experiments have shown that the averaged snow water equivalent before snowmelt for the Tayozhny Creek basin can increase in case of forest cutting by $15 \%$. The snow sublimation losses can decrease almost twice. The snowmelt rates after forest cutting turned out to be about $30 \%$ larger and the duration of snowmelt, on average, on 10 days longer. The simulated annual runoff from the Tayozhny Creek basin (mainly of snowmelt origin) averaged for 17 years appeared to be only about $10 \%$ higher than in case of forest cutting. However, its seasonal distribution and water balance components changed essentially. The spring flood peak discharge from the forested basin appeared to be, on average, 50\% lower, the spring floods started 5-7 days later and the flood recession turned out to be much longer. About $80 \%$ of the total runoff from the Tayozhny Creek basin is now subsurface flow, while in case of deforestation overland flow may become dominant. The numerical experiments were carried out to estimate the sensitivity of the hydrological cycle to changes of leaf area index as a forest age characteristic. The estimates obtained by simulation are quite consistent with the estimates obtained on the basis of experimental research.
\end{abstract}

Keywords: Hydrological cycle, runoff, modeling, forest basin, deforestation effects.

\section{INTRODUCTION}

The forest influence on the hydrological cycle and river runoff is one of the most debatable hydrological problems to which vast amount of literature are devoted. The carried out experimental studies have provided understanding of the main mechanisms of the hydrological cycle of forest basins and their interactions with forest ecosystems. However, results of these studies often contain contradictory estimations of hydrological role of the forest that can be explained by significant differences in physiographic conditions of the studied forest basins, climate variations and technologies of the experimental researches. Some forest effects on the hydrological cycle are obvious; however it is difficult to estimate them from experimental study.

Many experimental studies of forest influence on runoff were carried out on the basis of comparison of runoff measurements at the forested and deforested paired representative catchments or on the basis of comparison of runoff data for the same basins before and after deforestation. However such studies provide opportunities to obtain only crude estimations of hydrological role of the forest. The physiographic

*Address correspondence to this author at the Institute of Water Problems of the Russian Academy of Sciences, (IWP RAS), Moscow, Russia; Tel: (7 499) 135 5403; Fax: (7 499) 135 5415E-mail: kuchment@mail.ru conditions on the paired catchments have always some distinctions, whilst experimental investigations of runoff change using data obtained before and after deforestation can also give invalid results because of climate fluctuations.

It is possible to assume that most reliable quantitative assessment of runoff alterations, caused by changing of the forest density and forest type, can be done through mathematical modeling of the hydrological cycle. However, it is one of the most difficult problems in environmental modeling because of complicated interactions of hydrological, soil and biological processes and lack of necessary experimental information. These difficulties can explain a slow advance in solving this problem and most studies has been aimed on solution of partial tasks of this problem.

The most number of models is associated with evapotranspiration and soil moisture vertical transfer on forest plots (for example, Dickenson et al, 1991; Feddes et al., 2001; Emanuel et al., 2004; Kuchment and Demidov, 2004; Le Maitre and Versfeld, 1997, etc) [1-5]. Many publications are devoted to modeling of overland and subsurface flow in forest river basin (a review of such researches are given by Bonell (1998) [6]). Most of the models had been developed for describing separately vertical water transfer or horizontal water movement in the forest river basin for summer or winter periods as well. At the same time, there are only several investigations where horizontal and vertical hydrological 
processes in the forest basin have been considered together (Kuchment et al., 1990; Wigmosta et al., 1994) [7, 8].

In this paper, we present a model of the hydrological cycle of the forest basin for the whole hydrological year, including warm and cold seasons where are considered all main water balance components and their possible change at forest cutting. The case-study has been carried out on the basis of experimental observations on the Valday water balance station, situated in the Novgorod region (the mixed forest sub-zone in the west-northern part of Russia). The model has been constructed for the Tayozhny Creek experimental basin (Fig. 1). The basin is completely forested and its catchment area is $0.45 \mathrm{~km}^{2}$. The main forest type is fir with some mixture of birch, aspen and alder. The studied region is characterized by superfluous moistening. The mean annual precipitation amounts to $780 \mathrm{~mm}$. The snow cover is usually observed from the last third of November to the second half of April. The soils are of podzolic type and formed mainly on sandy loam and silt loam. The hydrographic network of the catchment is well-developed, however the creek channels are not deep and groundwater does not discharge into streams. The hydrometeorological data included the 3-hour measurements of precipitation, air temperature and humidity, cloudiness, wind speed, daily runoff, 5-day measurements of soil moisture, soil temperature, soil water evaporation, and transpiration, 10-day measurements of snow density, snow depth, and depth of frozen soil.

\section{MODELING PROCESSES OF HYDROLOGICAL CYCLE AND RUNOFF GENERATION IN THE FOR- EST BASIN}

\subsection{Interception of Liquid Precipitation by Forest Can- opy, Evapotranspiration and Soil Moisture Dynamics in the Warm Period}

The model used for description of these processes was published in (Kuchment and Demidov, 2006). It is assumed that a fraction (forest density) $U_{k}$ of liquid precipitation $P_{f}$ reaches the forest floor directly; the remaining part $\left(1-U_{k}\right)$ is intercepted by canopy and may be temporarily stored, evaporated or drained to the forest floor. It is supposed also that the canopy storage capacity is exponentially distributed over the canopy area with the maximum value $W_{c m}$. The evaporation from the wet part of canopy is calculated as

$$
E_{w}=\rho_{a} \frac{q^{*}\left(T_{f}\right)-q_{a}}{r_{a}} \eta \cdot\left(1-U_{k}\right)
$$

where $\rho_{a}$ is the air density, $q_{a}$ is the specific air humidity, $q^{*}\left(T_{f}\right)$ is the saturated specific air humidity at leaf temperature $T_{f}, r_{a}$ is the aerodynamic resistance for water vapor at the leaf surface.

Transpiration from dry leaves is calculated as

$$
E_{f}=\rho_{a} \frac{q^{*}\left(T_{f}\right)-q_{a}}{r_{a}+r_{s}} \cdot L A I
$$

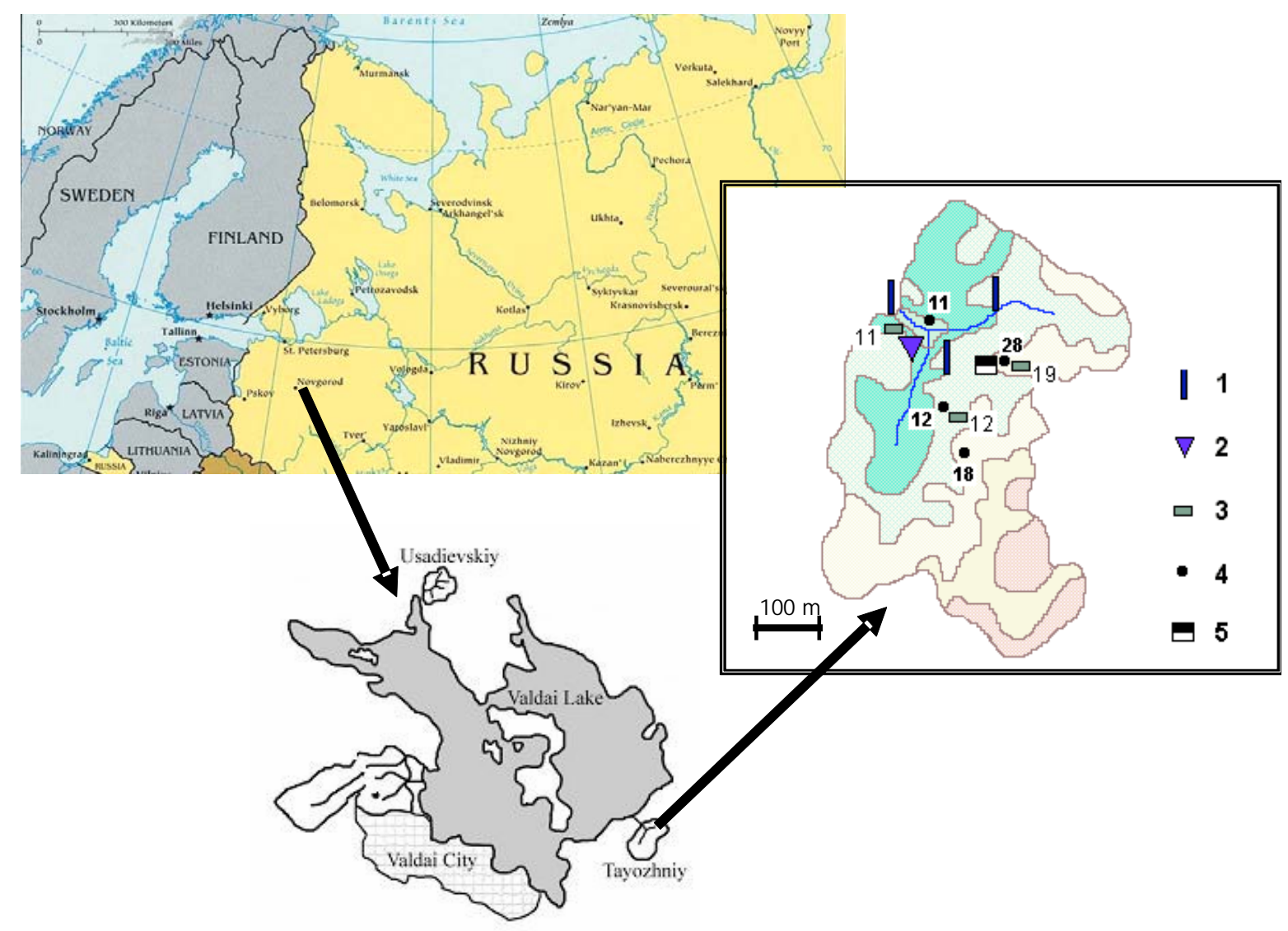

Fig. (1). Location of the Tayozhny Creek basin: 1-streamflow gauge at the basin outlet, 2-rain gauge, 3-soil moisture and temperature measurement points, 4-groundwater measurement points, 5-evapotranspiration gauge. 
where $L A I$ is the leaf area index, $r_{s}$ is the stomatal resistance calculated as

$r_{s}=r_{0} \frac{\theta_{f}-\theta_{r}}{\theta-\theta_{r}}\left(1+\frac{\gamma}{P A R}\right)$

where $r_{0}$ is the stomatal resistance at fully opened stomata, $\theta$ is the volumetric soil moisture content, $\theta_{f}$ is the moisture content at the field capacity, $\theta_{r}$ is the residual moisture content, PAR is the photosynthetically active radiation, $\gamma$ is an empirical coefficient.

The evaporation from bare soil $E_{g}$ is found using

$$
E_{g}=\rho_{a} \frac{r \cdot q^{*}\left(T_{g}\right)-q_{a}}{r_{a g}}
$$

where $r_{a g}$ is the resistance of the soil to evaporation, $T_{g}$ is the soil temperature, $r$ is the relative air humidity at the soil surface,

$$
r=\exp \left[\frac{M \cdot g \cdot \Psi(\theta)}{R \cdot\left(T_{g}+273\right)}\right]
$$

where $M$ is the molecular weight of water, $\mathrm{R}$ is the universal gas constant, $\psi(\theta)$ is the soil capillary potential at the top of the soil.

To describe vertical transfer soil moisture, the Richards equation in the diffusion form is used:

$$
\frac{\partial \theta}{\partial t}=\frac{\partial}{\partial z}\left[D(\theta) \frac{\partial \theta}{\partial z}-K(\theta)\right]-S_{k}(\theta, z),
$$

where $K(\theta)$ is the hydraulic conductivity of soil, $D(\theta)$ is the soil diffusivity, $z$ is the soil depth, $S(\theta, z)$ is the uptake of water by plant roots which is defined as:

$$
S_{k}(\theta, z)=-K(\theta)\left[\psi_{k}(\theta)-\psi(\theta)\right] \rho_{k}(z),
$$

where $\psi_{k}(\theta)$ is the capillary potential of the root system, $\rho_{k}(z)$ is the root density. It is assumed that $\rho_{k}(z)=\rho_{0} \exp \left(-k_{1} z\right)$, where $\rho_{0}$ is the root density in the upper layer of soil, $k_{1}$ is an empirical constant.

The soil surface temperature $T_{g}$ and the leaf temperature $T_{f}$ are calculated from the heat balance equations for canopy and soil. The system (1) - (7) was solved numerically with aid of an implicit finite difference scheme and a procedure described in (Kuchment and Startseva, 1991) [9].

\subsection{Snow Interception, Accumulation and Melt}

Physically based snow model describes processes of snow interception by forest canopy, sublimation and snow unloading from the canopy, snow accumulation, melting and sublimation on the forest floor taking into account the influence of canopy characteristics (forest density, tree structure, age, etc.) on radiation and turbulent heat fluxes. The model was presented in (Gelfan et al., 2004) [10] where it was used for snow processes simulation for the Tayozhny Creek and the neighboring open Usadiyevsky Creek experimental basins (the catchment area of the last basin is $0.44 \mathrm{~km}^{2}$ ).

\subsection{Vertical Heat and Moisture Transfer in a Frozen Soil}

Vertical moisture and heat transfer in the soil during soil freezing and thawing is described with the following equations (Kuchment et al. 1990) [7]:

$$
\begin{gathered}
\frac{\partial W}{\partial t}=\frac{\partial}{\partial z}\left(D \frac{\partial \theta}{\partial z}+D_{I} \frac{\partial I}{\partial z}-K(\theta, I)\right) \\
c_{T} \frac{\partial T}{\partial t}=\frac{\partial}{\partial z}\left(\lambda \frac{\partial T}{\partial z}\right)+\rho_{w} \tilde{n}_{w}\left(D \frac{\partial \theta}{\partial z}+D_{I} \frac{\partial I}{\partial z}-K(\theta, I)\right) \frac{\partial T}{\partial z}+\rho_{w} \chi \frac{\partial W}{\partial t}
\end{gathered}
$$

where $W, \theta$ and $I$ are the total water content, liquid water content and ice content of soil, respectively; $\left(W=\theta+\frac{\rho_{i}}{\rho_{w}} I\right)$; $T$ is the soil temperature; $\lambda$ is the thermal conductivity of soil; $D=K(\theta, I)\left(\frac{\partial \psi}{\partial \theta}\right)_{I}{ }_{I} D_{I}=K(\theta, I)\left(\frac{\partial \psi}{\partial I}\right)_{\theta} ; c_{T}=c_{e f f}+\rho_{w} L \frac{\partial \theta}{\partial T} ;$ $c_{\text {eff }}$ is the effective heat capacity of soil, $\chi$ is the heat of ice fusion, $K(\theta, I)$ is the hydraulic conductivity of frozen soil.

\subsection{Overland and Subsurface Flow}

To simulate overland and subsurface flow over the Tayozhny Creek basin, the basin area was schematized as a series of rectangular reaches located along the main channel, taking into account its small size. Overland flow along each of the schematized reaches was described by the equations (Kuchment et al., 1990) [7]:

$$
\begin{aligned}
& L \frac{d h}{d t}=R L-q_{l} \\
& h=\frac{m}{m+1}\left(\frac{q_{l} n_{l}}{i_{l}^{0.5}}\right)^{\frac{1}{m}}
\end{aligned}
$$

where $h$ is the average flow depth; $m$ is equal $5 / 3, L$ is the length of overland flow to the river; $R$ is the rate of overland flow generation per unit length; $q_{l}$ is the lateral overland inflow rate per unit channel length; $i_{l}$ is the slope of the overland flow; $n_{l}$ is the Manning's roughness coefficient.

It was assumed that the lower boundary of the soil layer under consideration has a small saturated hydraulic conductivity and the vertical water flux at this boundary is equal to its hydraulic conductivity.

It is also assumed that the horizontal movement of water in the soil layer under consideration occurs only if the soil moisture content exceeds the soil field capacity $\theta_{f}$. As a result, the subsurface flow is generated with the input rate $_{R_{g}}=\frac{\partial}{\partial t}\left[\left(\theta-\theta_{f}\right) z_{P}\right]$, where $z_{P}$ is the soil layer in which $\theta>\theta_{f}$.

Subsurface flow was described by the equations

$$
\begin{aligned}
& \left(\theta_{s}-\theta_{f}\right) L\left(\frac{d h_{g}}{d t}\right)=R_{g} L-q_{g}, \\
& h_{g}=\frac{q_{g}}{2 K_{g} i_{l}},
\end{aligned}
$$

where $q_{g}$ and $h_{g}$ are the discharge and the average depth of the subsurface runoff, respectively; $R_{g}$ is the inflow of sub- 
surface flow per unit length of the reach; $K_{g}$ is the coefficient of horizontal conductivity of soil. Because the channel travel time was small to comparison of numerical steps of input data, the total discharge at the outlet point of the Tayozhny Creek catchment was determined as the sum of overland and subsurface flow along the main channel.

\subsection{Calibration and Validation of the Model of Runoff Generation Processes in the Tayozhny Creek Basin}

The model was calibrated and validated by using as input data the 3-hour data sets of precipitation, air temperature, air humidity, wind speed and cloudiness measured at the meteorological station during the period from 1 May 1970 to 30 April 1975 (we had the most complete data for this period). Most of the model parameters were either assigned directly from soil and vegetation measurements in the Tayozhny Creek basin or calculated by empirical formulas based on experimental measurements in Russian and Canadian forests.

The parameters of the snow model were taken from (Gelfan et al., 2004) [10]. The hydraulic conductivity $K(\theta)$ and capillary potential $\psi(\theta)$ in (1) were calculated using formulas suggested by van Genuchten (1980) [11]. The parameters of these formulas (except the saturated hydraulic conductivity, $K_{s}$ ) are estimated from the measured soil constants and the relationships obtained in Gelfan (2006) [12]. The hydraulic conductivity $K(\theta, I)$ and capillary potential $\psi(\theta, I)$ of frozen soil were determined by transformation of the van
Genuchten's formulas taking into account the effects of ice and unfrozen liquid water content as suggested in (Gelfan, 2006) [12].

The saturated hydraulic conductivity $K_{s}$ and hydraulic conductivity at the lower boundary of the soil layer $K_{s}^{*}$ were calibrated against the measured soil moisture and temperature profiles. The minimum stomatal resistance of the forest canopy $r_{0}$ was adjusted against the evapotranspiration measurements.

Three model parameters (the horizontal hydraulic conductivity $K_{g}$, the Manning's roughness coefficient $n_{l}$, and the soil field capacity, $\theta_{f}$ ) were calibrated against runoff data at the Tayozhny Creek basin. The list of the parameters used in the model is presented in Table $\mathbf{1}$. The examples of simulation of soil moisture profiles and changes of soil temperature using the calibrated values of $K_{s}, K_{s}^{*}$ and $r_{0}$ are shown in Fig. (2). The runoff simulation results are shown in Fig. (3).

\section{SENSITIVITY OF THE HYDROLOGICAL CYCLE PROCESSES TO FOREST CUTTING}

The calibrated model of the hydrological cycle for the Tayozhny Creek basin was used for numerical experiments to study the effects of forest cutting on the hydrological cycle and the formation of river runoff. Taking into account the possible cutting effects on the soil and roughness constants, some parameters of the Tayozhny Creek basin model were

Table 1. The List of the Used Model Parameters

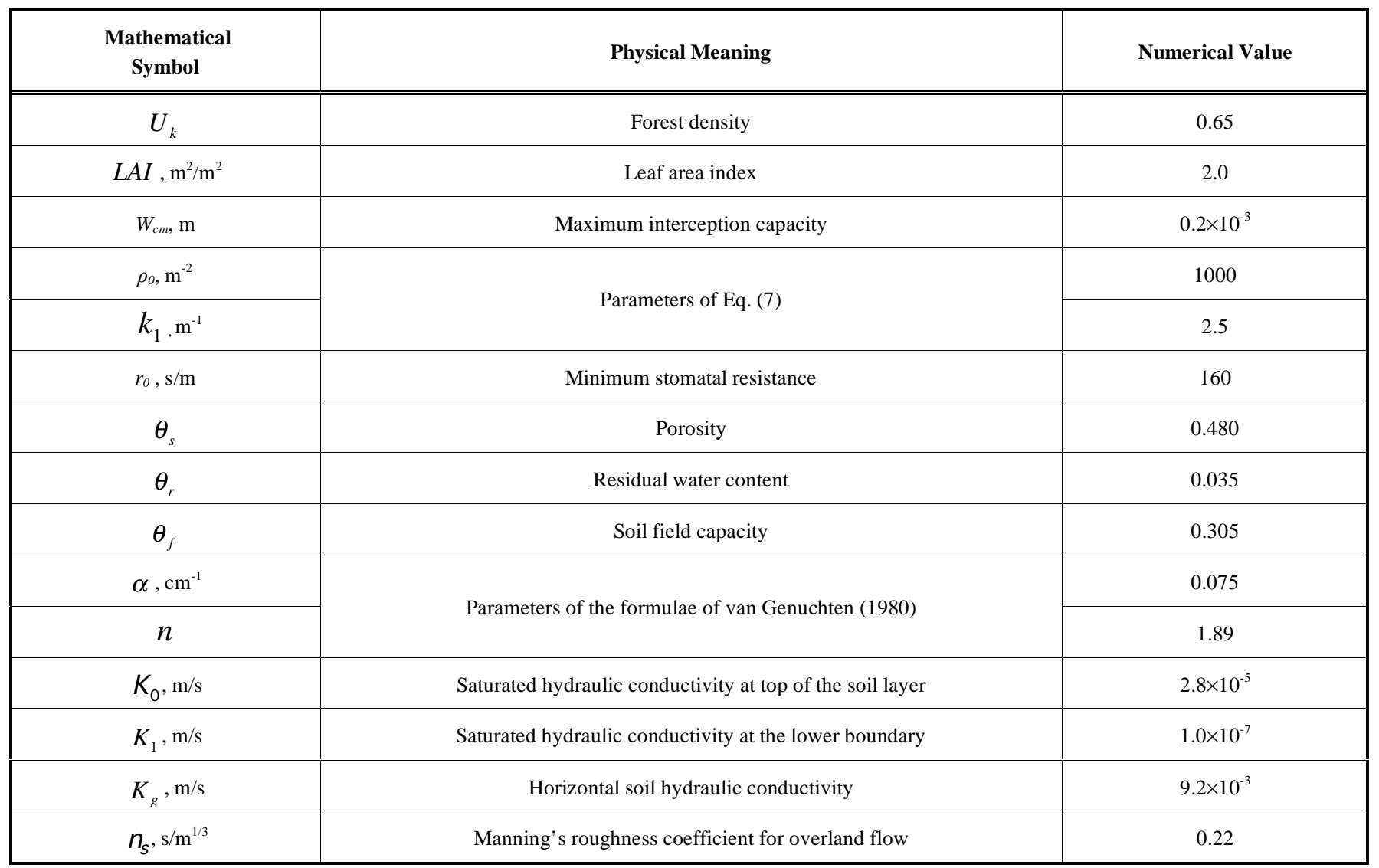



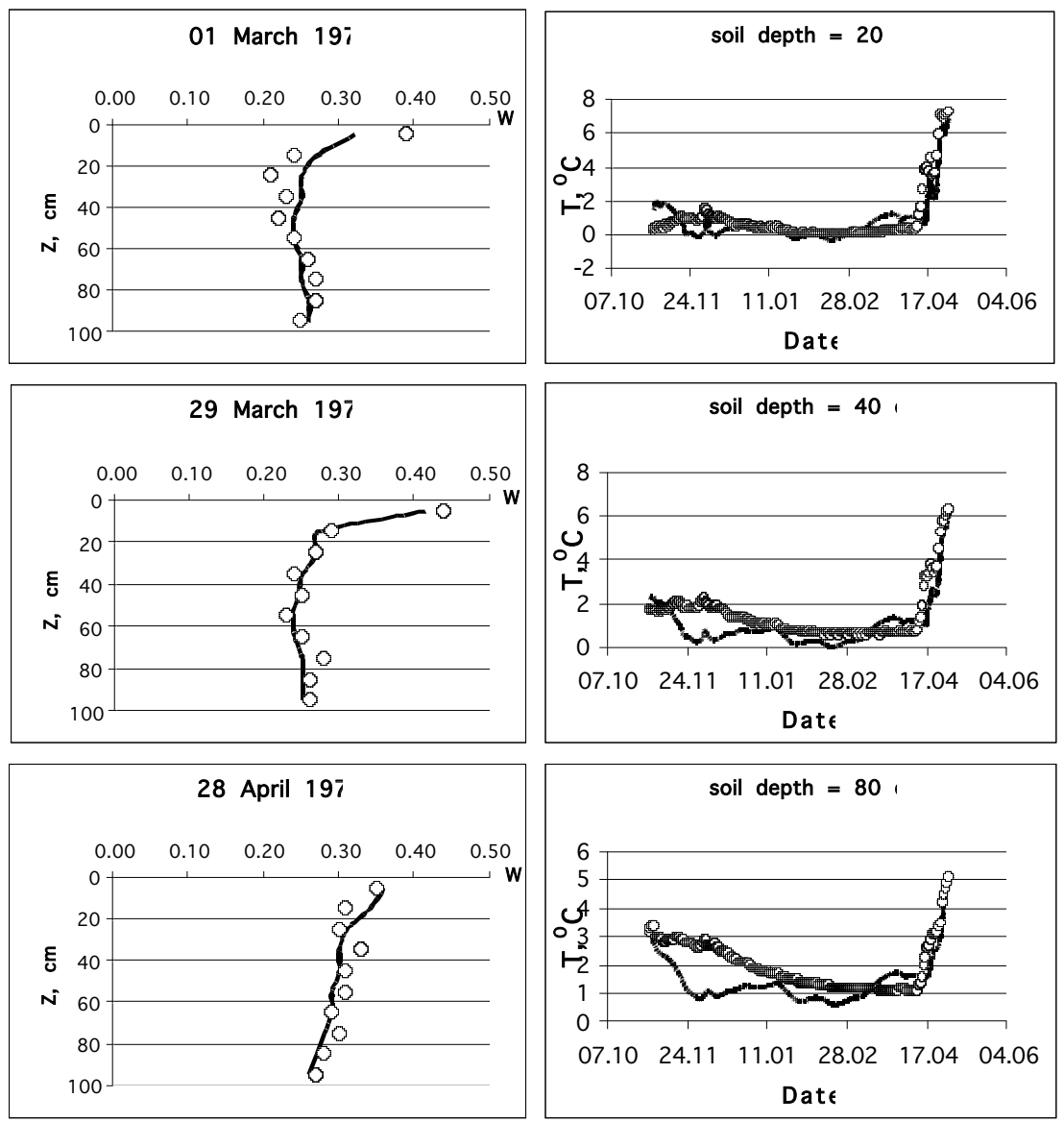

Fig. (2). Soil moisture profiles (left) and changes of soil temperature at different depths of soil (right). Points - measurements in the Tayozhny Creek basin; lines- simulation results.

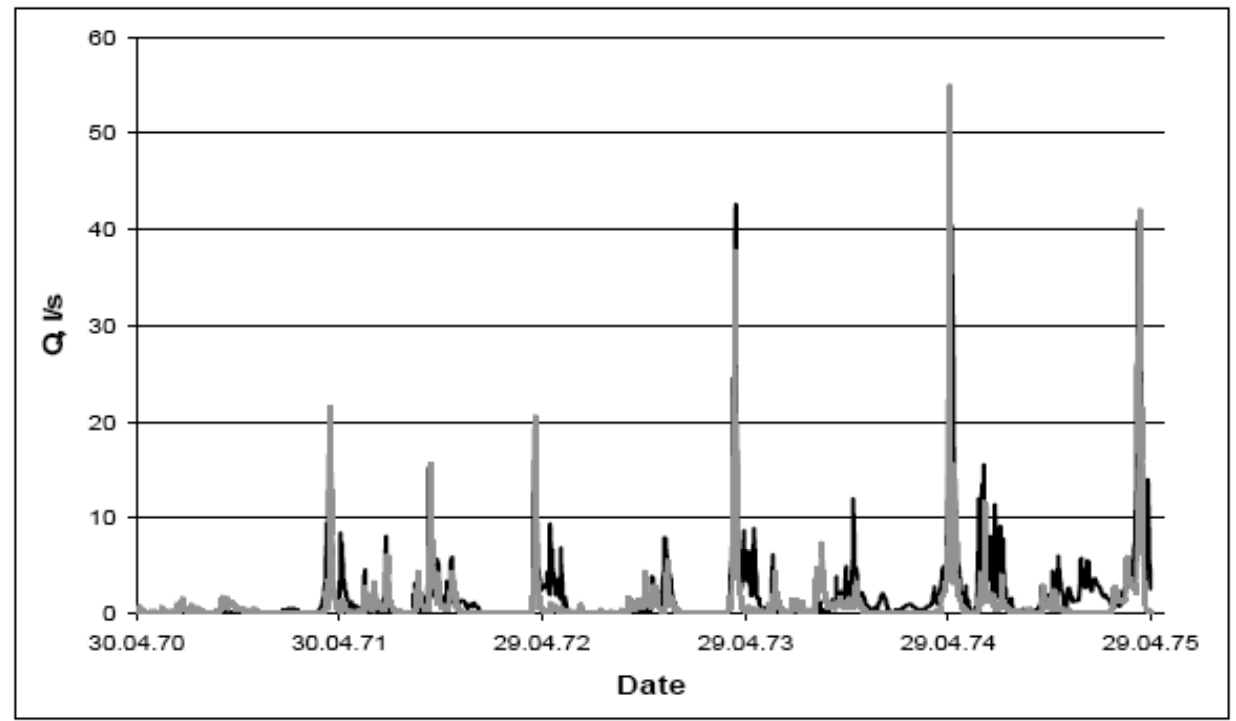

Fig. (3). Measured (black line) and simulated (grey line) hydrographs at the outlet runoff gauge of the Tayozhny Creek basin.

changed according to observations at the neighbouring deforestated Usadevsky Creek basin that has the same physiographic and climate conditions (see Table 2). Then the input hydrometeorological data for 17 years (1967-1983 years) were used to simulate the hydrological cycle of the Tayozhny Creek basin during this period for present day forest conditions and for the assumption that this basin area would be completely deforested. Some results of this simulation are presented below.

\subsection{Influence of Forest Cutting on Formation of Snow Cover and Snowmelt}

The comparison of the results of numerical simulation of snow characteristics has shown that the average for 17 years 
Table 2. The List of the Parameters Assigned for the Tayozhny Creek Basin to Study the Effects of Forest Cutting

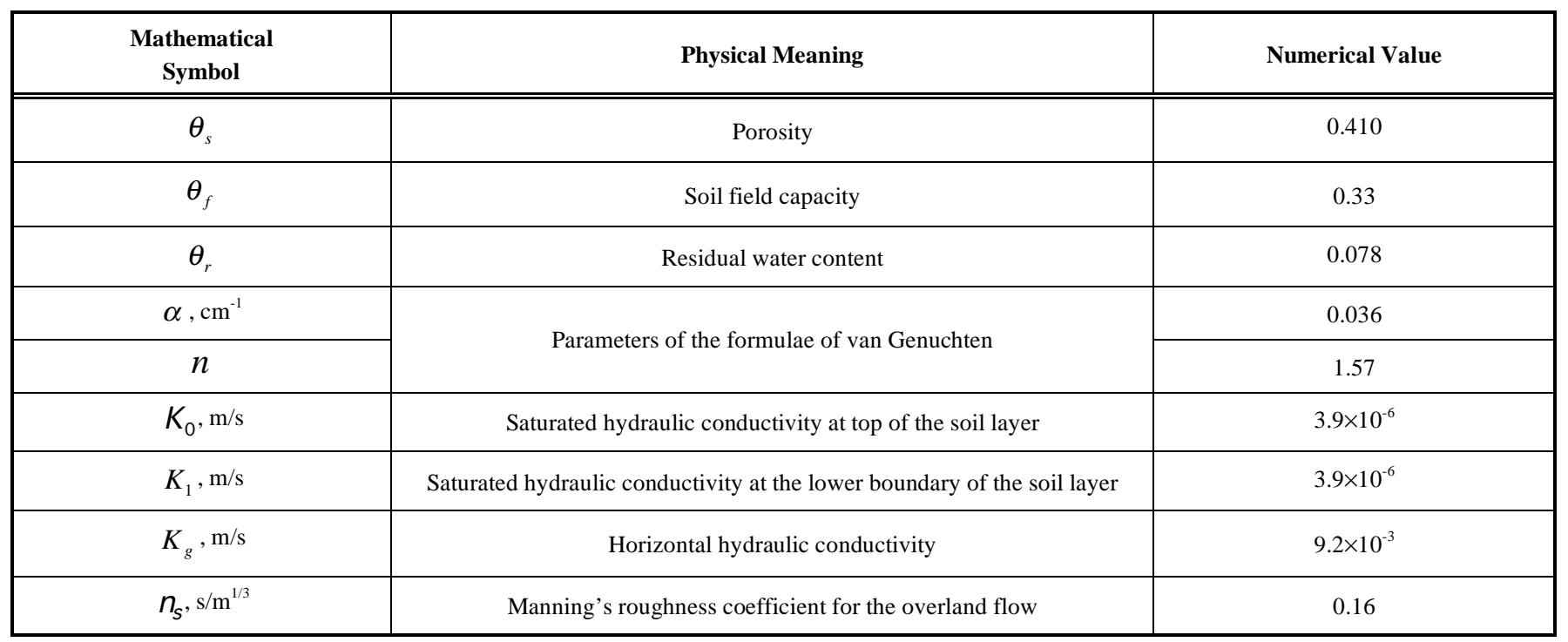

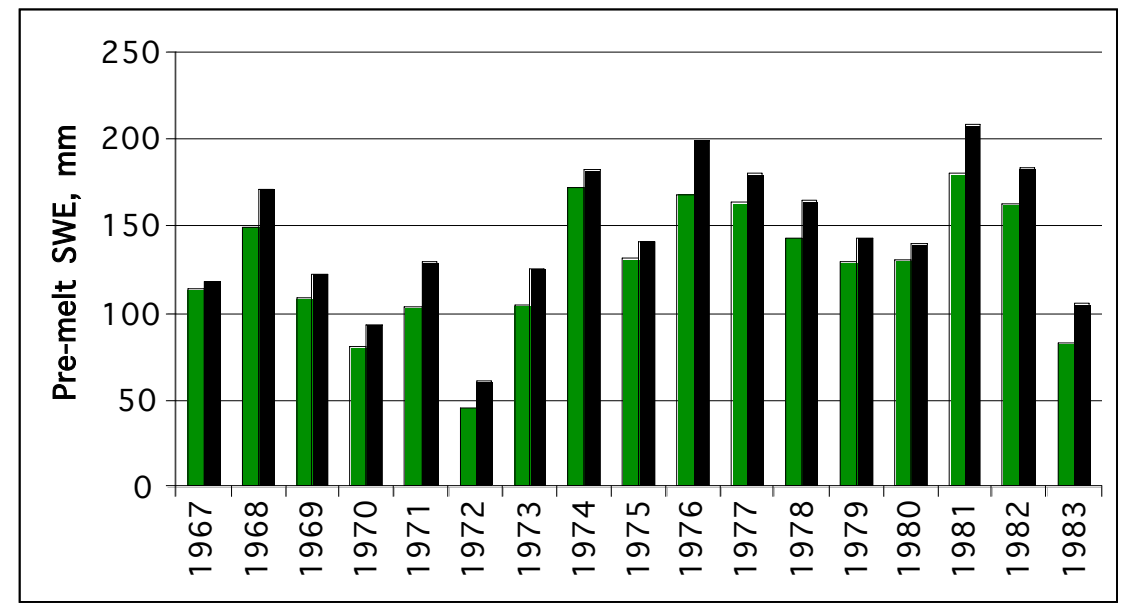

Fig. (4). Influence of forest cutting on the pre-melt snow water equivalent: green bars - forest plots, black bars -open areas.

snow water equivalent (SWE) before snowmelt for the Tayozhny Creek basin is by $15 \%$ higher of the corresponding value for this basin after forest cutting. However, this difference in SWE varies from year to year (Fig. 4).

The main cause of this variation of SWE may be the differences in the rate of snow sublimation in the forest and in the open areas. The total SWE losses caused by sublimation in the forest, summarizing the sublimation of intercepted snow and snow on the forest floor, are compared with the snow sublimation losses on the open areas in Fig. (5).

The calculated rates of snowmelt for the forested and deforested plots, averaged for cold period of each year, are presented in Fig. (6). For all years, the snowmelt rates in the forest are smaller and the duration of snowmelt is, on average, 10 days longer. In the cases with repeated freezing of melt water in snow cover, the duration of snowmelt in the forest was up to 3 weeks longer than on the deforested areas.

\subsection{Influence of Forest Cutting on Hydrothermal Regime of Soil in Cold Period}

The carried out numerical simulation allows us to estimate the soil freezing depth change resulted from forest cut- ting. The reduction of the long-wave radiation on the surface of the snow cover after forest cutting leads to an increase of the freezing depth, however, this depth can also decrease because the snow depth in the deforested areas can be larger than in the forest. In addition, the upward water transfer from an unfrozen part of soil to the freezing front is more intensive in the deforested areas and this water transfer detains soil freezing. As a result, the soil freezing depth in the deforested areas is more sensible to meteorological conditions than in the forest.

\subsection{Influence of Forest Cutting on River Runoff Genera- tion}

The simulated annual runoff from the Tayozhny Creek basin averaged for 17 years $(181 \mathrm{~mm})$ is higher than the same runoff from this basin after deforestation $(166 \mathrm{~mm})$. The comparison of seasonal runoff before and after forest cutting is given in Fig. (7) where the runoff hydrographs calculated on the basis of the meteorological data of 1970-1973 years are presented. For the forest basin, the spring flood peak discharges are, on average, 50\% lower, the spring floods start 5- 


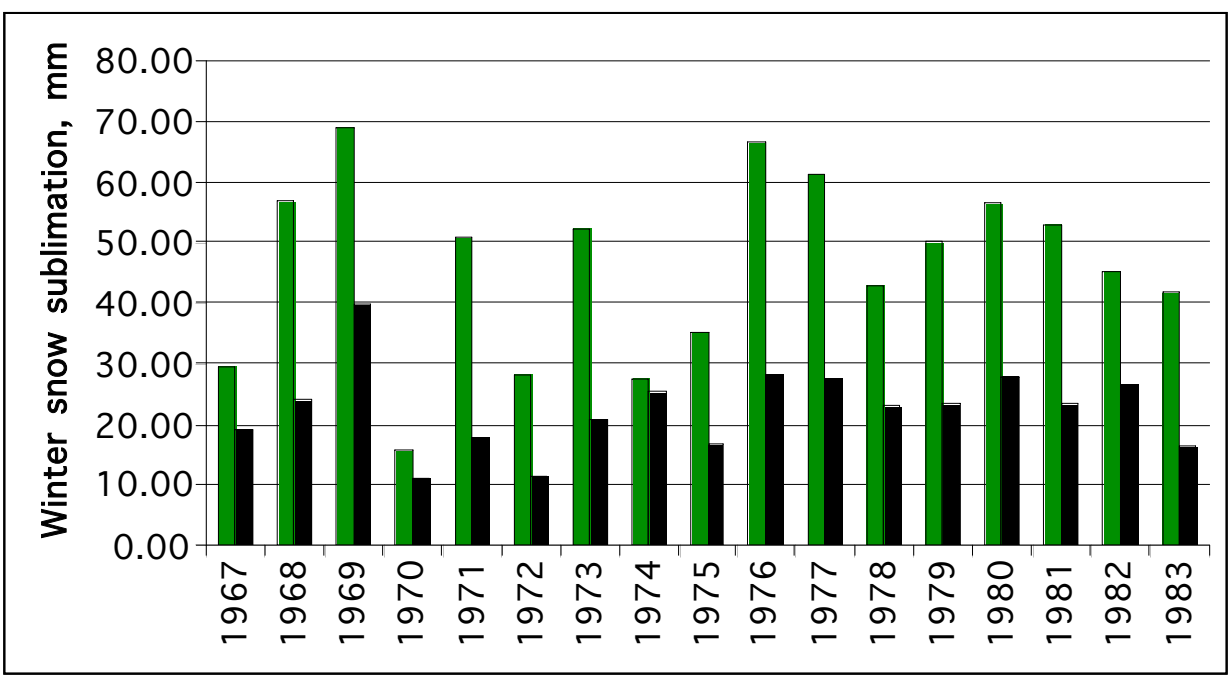

Fig. (5). Influence of forest cutting on snow sublimation: green bars - forest plots; black bars - open areas.

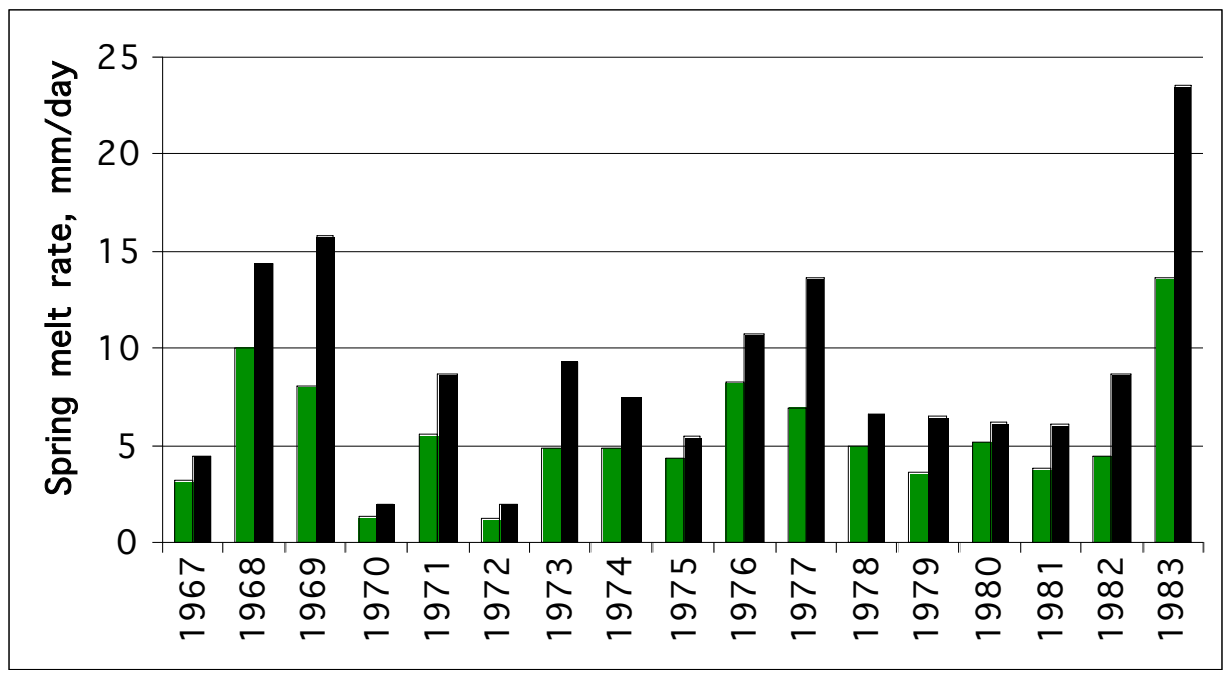

Fig. (6). Influence of forest cutting on snowmelt rate: green bars - forest; black bars -deforested area.

7 days later and the flood recession is much longer than for deforested basin.

Rainfall floods in forested watersheds are also less intense, but are formed more frequently than in the deforested basin. About $80 \%$ of the total runoff from the forest basin for the simulation period was generated as a result of subsurface flow, while overland flow was generated seldom, e.g. during intense rainfall on saturated soil in the autumn or at the beginning of snowmelt. Fig. (8) shows the contribution of overland runoff in the formation of autumn and spring floods for a year. At the deforested areas, the overland flow dominates.

\section{SENSITIVITY OF THE HYDROLOGICAL CYCLE PROCESSES TO CHANGES OF LAI AND FOREST AGE}

$L A I$ is one from representative characteristics of forest age. In the process of life of spruce forests, the value of $L A I$ varies from 0.5 reaching 5.0 for middle-aged forest and decreasing to 2 for old forest. The decrease of LAI causes changes of liquid water and snow interception capacity, transmittance of short-wave radiation, transpiration, evaporation from the soil. The calibrated model of the Tayozhny Creek basin was applied for simulation of hydrological processes at different LAI using the measured meteorological data during the warm period and the cold period of the year.

The numerical experiments for the warm period were carried out on the basis of the measured meteorological data for the period from 24 May to 15 September of 1971-1973 years. The results of numerical experiments presented in Table 3 show a significant variation in the components of water balance with changing $L A I$. According to the calculations, at $L A I=1$ that is typical for young forest, the transpiration is less than $20-27 \%$ of the transpiration of the mature forest $(L A I=5)$; the transpiration in the old forest $(L A I=2)$ is less than the transpiration of the mature forest by $6-23 \%$. In young and middle-aged forest, the evapotranspiration is higher than in the old forest, respectively, at $3-21 \%$ and $4-$ $12 \%$. The rainfall runoff for the period under consideration was very small (comparable with the errors of simulation).

To investigate the effect of $L A I$ on snow dynamics and snowmelt runoff of the Tayozhny Creek basin, the value of 

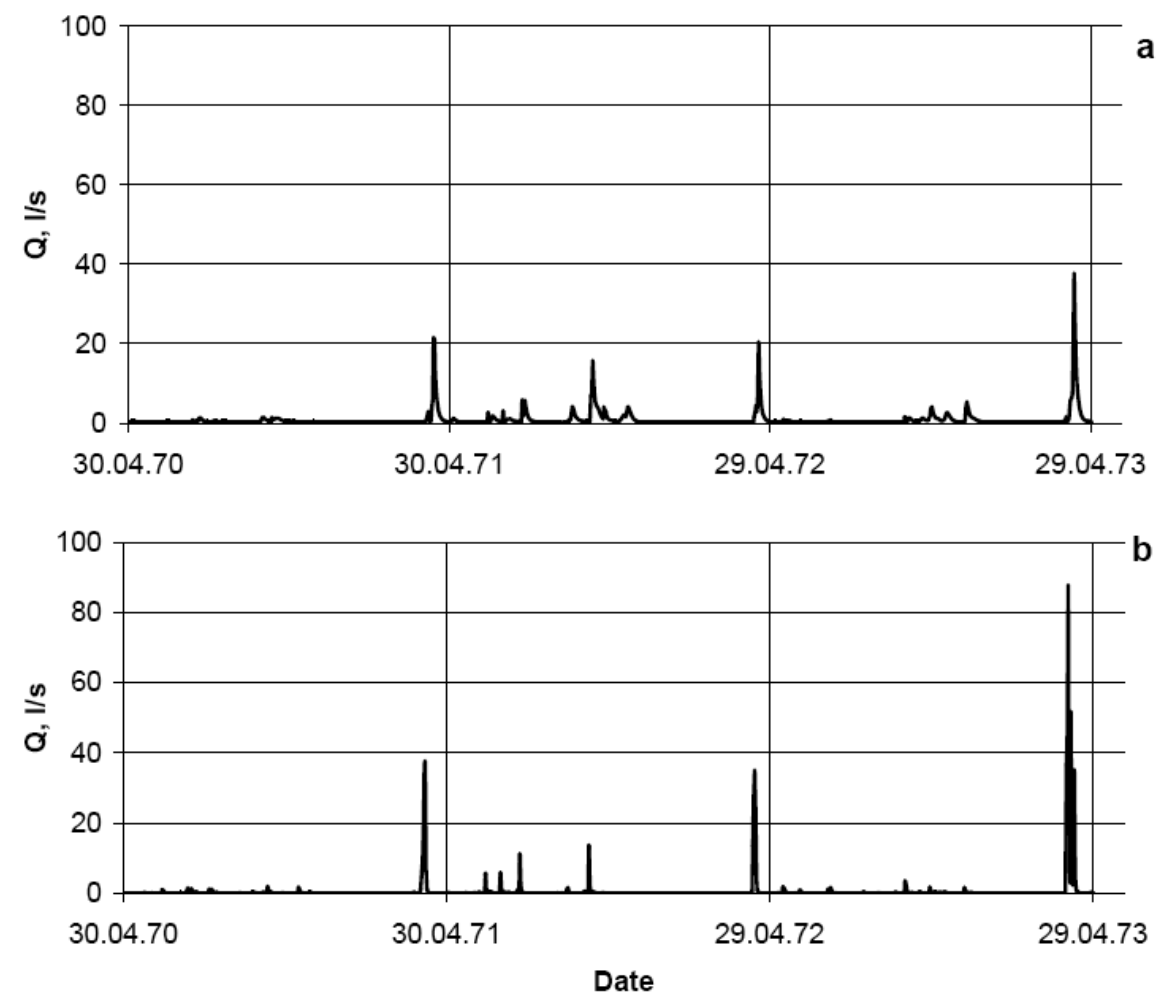

Fig. (7). Influence of forest cutting on river runoff: a) the forest basin; b) the deforested basin.

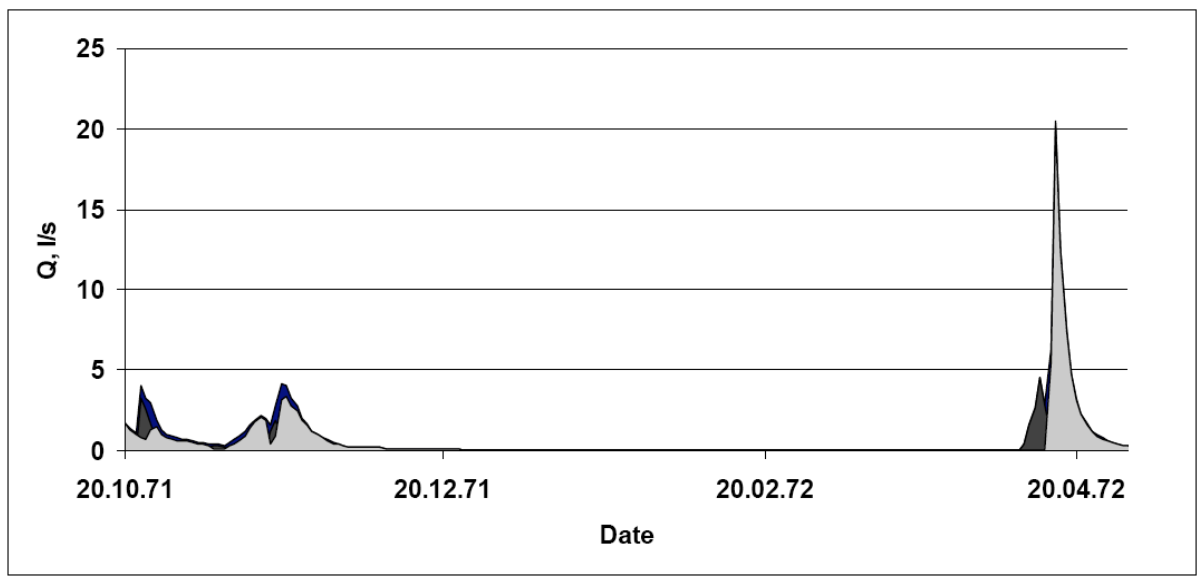

Fig. (8). Contributions of overland flow (black areas) and subsurface flow (gray areas) to the total runoff from the forested catchment.

LAI was varied from 0.5 to 4.0 that resulted in significant changes in snow interception capacity and transmittance of short-wave radiation.

Using the meteorological data for 1971-1975 years, the estimation of snowmelt runoff sensitivity to $L A I$ was carried out (Figure 9). As can be seen from (Fig. 9), the volume of snowmelt runoff slightly increases with the growth of $L A I$ from 0.5 to 1.6 and decreases with the continuing growth of $L A I$ from 1.6 to 5.0. Such changes of snowmelt runoff with growth of $L A I$ are generally similar for different river forest basins but magnitude and rate of these changes may be rather different.

\section{CONCLUSION}

Experimental studies of the influence of the forest on the hydrological cycle and runoff generation on the basis of the observations at forested and deforested paired representative catchments or by comparison of runoff data before deforestation and after deforestation provide an opportunity to obtain only crude estimations of hydrological role of forest. The physiographic conditions on the paired catchments have always some distinctions. Experimental investigation of changing of the hydrological cycle using data obtained before deforestation and after deforestation can also give invalid results because of climate fluctuations. It seems that reliable quantitative assessment of alteration of hydrological cycle of a river basin caused by changing of the forest density and the forest type can be done through mathematical modeling of the hydrological cycle only. However, it is one of the most difficult problems in environmental modeling because of complicated interactions of hydrological, soil and biological processes and lack of necessary experimental information. In this paper, an attempt to develop a physically based model for prediction of possible changes of the hydro- 
Table 3. Influence of LAI on the Components of Water Balance (in mm) of the Tayozhny Creek Basin Calculated for the Periods from 24 May to 15 September

\begin{tabular}{|c|c|c|c|c|c|c|c|c|c|}
\hline \multicolumn{10}{|c|}{ Years } \\
\hline & \multicolumn{3}{|c|}{$\begin{array}{l}1971 \\
L A I\end{array}$} & \multicolumn{3}{|c|}{$\begin{array}{l}1972 \\
L A I\end{array}$} & \multicolumn{3}{|c|}{$\begin{array}{r}1973 \\
L A I\end{array}$} \\
\hline & 1 & 5 & 2 & 1 & 5 & 2 & 1 & 5 & 2 \\
\hline Rainfall & 340.0 & 340.0 & 340.0 & 118.0 & 118.0 & 118.0 & 316.0 & 316.0 & 316.0 \\
\hline Transpiration & 154.2 & 237.6 & 193.5 & 119.3 & 174.6 & 164.4 & 158.1 & 245.0 & 208.6 \\
\hline $\begin{array}{l}\text { Evaporation under the } \\
\text { forest canopy }\end{array}$ & 146.3 & 2.2 & 23.8 & 76.0 & 1.2 & 12.3 & 126.1 & 2.5 & 22.0 \\
\hline $\begin{array}{l}\text { Evaporation from the forest } \\
\text { canopy }\end{array}$ & 33.8 & 71.0 & 58.0 & 14.6 & 35.5 & 26.1 & 30.0 & 61.0 & 52.1 \\
\hline Evapotranspiration & 334.3 & 310.8 & 275.3 & 209.9 & 211.3 & 202.9 & 314.2 & 308.5 & 282.7 \\
\hline $\begin{array}{l}\text { Measured evapotranspira- } \\
\text { tion }\end{array}$ & - & - & 268.0 & - & - & 238.0 & - & - & 225.0 \\
\hline
\end{tabular}

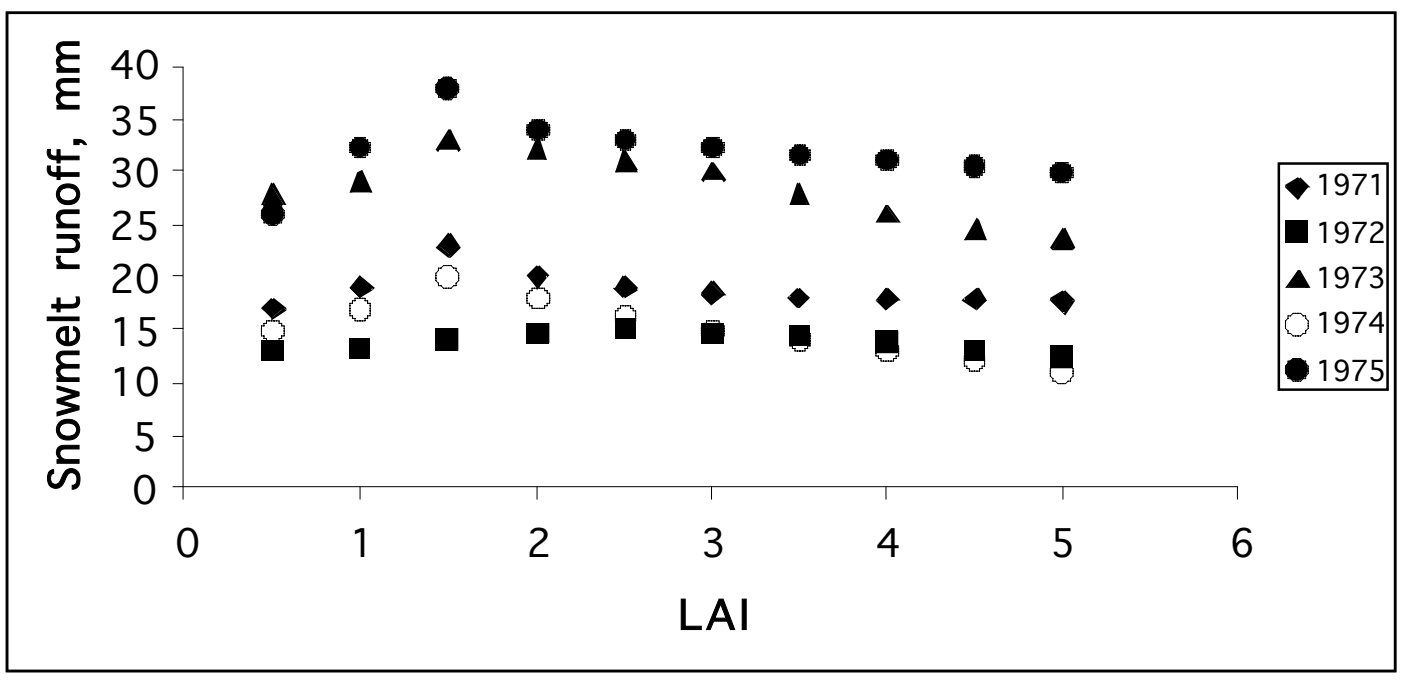

Fig. (9). Sensitivity of the simulated snowmelt runoff to $L A I$.

logical cycle and runoff caused by human activity on a forest river basin has been made. The model allows one to simulate the hydrological cycle and river runoff generation in a forest basin for the whole hydrological year and includes the description of main hydrological processes: liquid water and snow interception by forest canopy, snow accumulation and melt, vertical soil moisture transfer and evapotranspiration, overland, subsurface and channel flow. Most of the model parameters were either assigned directly from soil and vegetation measurements or calculated by empirical formula based on experimental measurements. The model has been validated using hydrometeorological observations at a small completely forested experimental basin and the sensitivity of the hydrological cycle to deforestation of this basin was estimated. The obtained estimates are quite consistent with the estimates obtained from the experimental research described in scientific literature. Opportunities of application of the suggested model depend on availability of information on soil and vegetation characteristics of a forest basin and pos- sibilities to conserve the calibrated parameters after change of the land use.

\section{ACKNOWLEDGEMENTS}

This study has been supported by the Russian Foundation of Fundamental Research.

\section{REFERENCES}

[1] Dickenson RE, Henderson-Sellers A, Rosenzweig C, Sellers PJ. Evapotranspiration models with canopy resistance for use in climate models, A review. Agric for Meteorol 1991; 54: 373-88.

[2] Feddes RA, Hoff H, Bruen M, et al. Modeling root water uptake in hydrological and climate models. Bull Am Meteorol Soc 2001; 82: 2797-809.

[3] Emanuel RE, D'Odorico PD, Epstein HE. A dynamic soil water threshold for vegetation water stress derived from stomatal conductance models. Water Resour Res 2007; 43: WO3431, DOI: 10 1029/2005 WR004831.

[4] Kuchment LS, Demidov VN. Modeling of influence of hydrological processes on the carbon cycle of a forest ecosystem. Environ model software 2006: 21: 111-4. 
[5] Le Maitre DC, Versfeld DB. Forest evaporation models: Relationships between stand growth and evaporation. J Hydrol 1997; 193: 240-57.

[6] Bonell M. Selected challenges in runoff generation research in forests from the hillslope to headwater drainage basin scale. J Am Water Resour Assoc 1998; 34(4): 765-85.

[7] Kuchment LS, MotovilovYuG, Nazarov NA. Sensitivity of hydrological systems (in Russian). M Nauka 1990.

[8] Wigmosta MS, Vail LW, Lettenmaier DP. A distributed hydrologyvegetation model for complex terrain. Water Resour Res 1994; 30(6): 1665-79.

[9] Kuchment LS, Startseva ZP. Sensitivity of evapotranspiration and soil moisture changes in climate and direct effects of carbon dioxide. J Hydrol Sci 1991; 36(2): N 12.
[10] Gelfan AN, Pomeroy JW, Kuchment LS. Modeling forest cover influences on snow accumulation sublimation and melt. J Hydrometeorol 2004; 5(5): 785-803.

[11] Van Genuchten MTh. A closed form equation for predicting the hydraulic conductivity of unsaturated. Soil Sci Soc Am J 1980; 44: 892-8.

[12] Gelfan AN. Physically based model of heat and water transfer in frozen soil and its parameterization by basic soil data. In: M. Sivapalan et al. (Eds) Predictions in Ungauged Basins: Promises and Progress. Proceedings of symposium S7 held during the Seventh IAHS Scientific Assembly at Foz do Iguazu, Brasil, April 2005, IANS Publ., 303, 2006: pp. 293-304.

(C) Kuchment et al.; Licensee Bentham Open.

This is an open access article licensed under the terms of the Creative Commons Attribution Non-Commercial License (http://creativecommons.org/licenses/by-nc/3.0/) which permits unrestricted, non-commercial use, distribution and reproduction in any medium, provided the work is properly cited. 